\title{
USING CARBONIZED REFUSE DERIVED FUEL TO RESTORE SEAWEED FORESTS: A POTENTIAL CONSERVATION TECHNIQUE
}

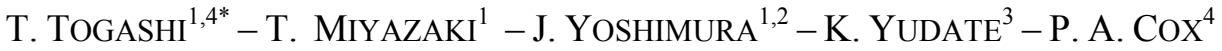 \\ ${ }^{I}$ Marine Biosystems Research Center, Chiba University, Kamogawa, 299-5502, Japan \\ ${ }^{2}$ Faculty of Engineering, Shizuoka University, Hamamatsu, 432-8561, Japan \\ ${ }^{3}$ JFE Steel Corporation, Uchisaiwaicho 2-2-3, Tokyo, 100-0011, Japan \\ ${ }^{4}$ Institute for Ethnomedicine, Box 3464, Jackson Hole, Wyoming 83001, USA \\ (phone: +81-4-7095-2201; fax: +81-4-7095-2271) \\ e-mail:togashi@faculty.chiba-u.jp \\ (Received $27^{\text {th }}$ Febr 2007 ; accepted $13^{\text {th }}$ May 2007)
}

\begin{abstract}
We have recently developed a new material by carbonizing refuse derived fuel (RDF) not discharging dioxin and other toxic fine particles. This recycled carbonaceous material (CRDF) has two major good points: 1) rich in the three chemical elements of fertilizer (nitrogen, phosphoric acid and potassium) and 2) a good adsorbent like activated charcoal. In this study, making the best use of these merits, we looked into the possibility of using this material to restore seaweed forests that were damaged by human activities. We confirmed that no toxic substance was liquated out from this material. In the laboratory experiments, the growth of a species of marine green algae (Derbesia tenuissima (Moris et De Notaris) Crouan) was accelerated by this material. CRDF might supply nitrogen short in seawater as the form of nitrate. Our technique was actually effective to introduce marine algae in the fields using a series of test plates that included this material ranging from 0 to $8.2 \%(\mathrm{w} / \mathrm{w})$. We might not only recover biodiversity in coastal ecosystems by restoring seaweed forests but also remarkably reduce atmospheric $\mathrm{CO}_{2}$ released in the process of the incineration of waste with this technique.
\end{abstract}

Keyword: atmospheric $\mathrm{CO}_{2}$, biodiversity, coastal ecosystems, carbonaceous material, water pollution

\section{Introduction}

Refuse derived fuel (RDF) is produced from municipal solid waste (MSW) through following processes: separating at source; sorting or mechanical separation; size reduction (shredding, chipping and milling); separation and screening; blending; drying and palletizing [3]. The waste material is screened to remove the recyclable fractions (e.g. metals), the inert fractions (e.g. glass) and the fine wet putrescible fractions (e.g. food) before being pulverized. The calorific power of RDF is approximately $5000 \mathrm{kcal}$ $\mathrm{kg}^{-1}$, which is similar to that of coal. RDF is often used to generate electricity. In Japan, however, since a serious accident at an electric power plant using RDF in Mie prefecture in 2003, the demand of RDF is decreasing. It would be, therefore, important to find another way to use RDF effectively and safely.

We have recently developed a new carbonaceous material with RDF. In the producing process, we pyrolyze RDF without oxygen at a very high temperature $\left(>1000^{\circ} \mathrm{C}\right)$, so dioxin and other toxic gasses are not produced. We can also use thermal energy left over in the iron manufacture processes not to generate additional $\mathrm{CO}_{2}$. By carbonization, the weight of waste is decreased by ca. $12.5 \%$. We call this material CRDF. We found that CRDF has some chemical and physical good points. First, it is rich in the three chemical elements of fertilizer (i.e. nitrogen, phosphoric acid and potassium). In our preliminary research, these percentages are $1.7,3.0$ and $1.1 \%(\mathrm{w} / \mathrm{w})$, 
respectively. Second, it is a good adsorbent like activated charcoal. This appears to be due to a large surface area (i.e. $140 \mathrm{~m}^{2} \mathrm{~g}^{-1}$ in our preliminary research).

The inshore fishery is one of very important industries in many countries including Japan. Fishery products have been key sources of food since early times, constituting $20 \%$ of the Japanese people's protein consumption (see the Japanese government annual report on the fisheries at http://www.maff.go.jp/eindex.html). Many commercially important fish populations, however, have been declining in the past several decades [5, 10]. One of the major reasons for decreasing fisheries is destruction of seaweed forests by human activities. Seaweed forests play significant roles in maintaining biodiversity of coastal marine ecosystems (e.g. [7]). Marine algae are not only foods for herbivores, but also provide spawning and hiding places for juveniles of many marine organisms. For instance, settlement and germination of seaweed spores are seriously disturbed by species of coralline red algae (e.g. [6] for Lithophyllum yessoense Foslie), which is exacerbated by human activities (see [8]). In this study, we carefully examine whether CRDF could be used to solve these crucial environmental problems restoring seaweed forests.

\section{Materials and methods}

\section{Scanning electron microscope observations}

The surface ultrastructures of the carbonaceous material were observed using a scanning electron microscope (SEM, Hitachi S-2050). We prepared a series of samples varying the proportion of the carbonaceous material (i.e. 3, 20 and $90 \% \mathrm{w} / \mathrm{w}$ ) using starch as a binder.

\section{Eluent test}

We checked whether 24 chemical compounds were eluted from CRDF: alkylmercury, organic mercury, inorganic mercury, cadmium, lead, organophosphorus, chromium 6, arsenic, total cyanide, poly chlorinated biphenyl, trichloroethylene, tetrachloroethylene, 1,2-dichloroethane, 1,1-dichloroethylene, cis-1,2-dichloroethylene, 1,1,1-trichloroethane, 1,1,2-trichloroethane, 1,3-dichloropropene, thiuram, simazine, thiobencarb, benzene and selenium. Such tests are necessary for materials made from municipal solid waste (MSW). For the metals, Inductively Coupled Plasma Mass Spectrometer (ICP-MS) was used and a Mass Spec was used for the rest.

\section{Laboratory study}

\section{Materials}

We used male gametophytes of a dioecious marine green alga, Derbesia tenuissima (Derbesiaceae) in our laboratory experiments. They usually do not branch out (Fig. 1; [16]). We safely estimated their biomass (volume) assuming the shape of each gametophyte as ellipsoidal (volume $(V)=4 / 3 \pi \mathrm{ab}^{2}$, a: radius on the minor axis; b: radius on the major axis) [4], and easily and correctly measured the growth rate of this alga. We used only male gametophytes because female gametes parthenogenetically develop into filamentous sporophytes. For each culture experiment, we prepared even-sized small ellipsoidal male gametophytes of D. tenuissima, culturing protoplasts in PES 
medium at $25^{\circ} \mathrm{C}$ under a $14: 10$, light : dark condition using an incubator (NK system) [17].

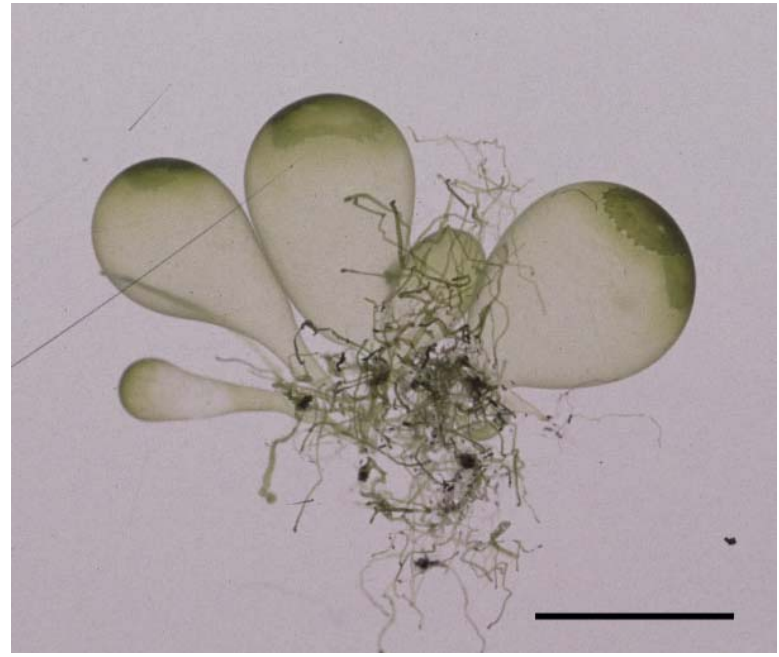

Figure 1. Male gametophytes of Derbesia tenuissima. Both male and female gametophytes are similarly ellipsoidal in shape. Scale bar $=2 \mathrm{~cm}$.

\section{Culture experiments}

The grained CRDF was fixed on the bottom of cylindrical glass vessels $(3 \mathrm{~cm}$ in radius and $8.5 \mathrm{~cm}$ in depth) with $50 \mathrm{~mL}$ of $1 \%$ agar (Wako). Five male gametophytes of D. tenuissima were cultured in each vessel with $100 \mathrm{~mL}$ seawater at $25{ }^{\circ} \mathrm{C}$ under a 14:10, light : dark condition. We explored three different experimental regimes: 1) $5 \mathrm{~g}$ of CRDF; 2) $15 \mathrm{~g}$ of CRDF; 3) $1 \%$ agar only (control). The size of each gametophyte (i.e. radii on the minor and major axes) was measured every week and the volume was calculated. At the beginning of the experiments, there was no significant difference in the mean volumes of gametophytes among the regimes. Seawater used in the culture experiments was drawn at the field study site (below) and autoclaved $\left(121{ }^{\circ} \mathrm{C}, 20 \mathrm{~min}\right.$ ) before use. Chemical characters of seawater (i.e. $\mathrm{pH}$ and the densities of $\mathrm{NO}_{3}^{-}, \mathrm{NO}_{2}^{-}$, $\mathrm{PO}_{4}{ }^{3-}$ and $\mathrm{NH}_{4}{ }^{+}$) after the two experiments (i.e. $15 \mathrm{~g}$ of CRDF and $1 \%$ agar only) were analyzed using High Performance Liquid Chromatography (HPLC).

\section{Field study}

Our field study was carried out at our study site in the preserved area of the Marine Biosystems Research Center of Chiba University located in the Boso peninsula, Japan $\left(35^{\circ} 08^{\prime} \mathrm{N}, 140^{\circ} 11^{\prime} \mathrm{E}\right)$ in 2004 . Samples of seawater were weekly collected from July to December. Ammonium, Nitrate, Nitrite and Reactive phosphorus were quantitatively analyzed using HPLC. We calculated the ratios of TIN $(\mathrm{N}=$ Ammonium + Nitrate + Nitrite) to RP ( $\mathrm{P}=$ Reactive phosphorus) and compared them with the Redfield ratio [13]. [The Redfield ratio refers to the molar ratio of carbon (C), nitrogen $(\mathrm{N})$ and phosphorus $(\mathrm{P})$ in plants estimated by using phytoplankton. When nutrients are not limiting, they have the following molar ratio of elements: $\mathrm{C}: \mathrm{N}: \mathrm{P}=106: 16: 1$. Thus $\mathrm{N}: \mathrm{P}$ ratios less than 16 mean they are under nitrogen limiting conditions, and vice versa.]

We made a series of test plates that include the carbonaceous material (i.e. 0, 2.7, 2.9, 5.3 and $8.2 \% \mathrm{w} / \mathrm{w}$ ) with the 'eco-concrete' that was made from ash of waste to 
keep the shape in sea (Fig. 2). These five plates were fixed in the upper intertidal zone during a low tide using stainless bolts making a pentagon [12]. We visited them monthly and counted the numbers of individuals of each species of seaweeds growing on each plate.

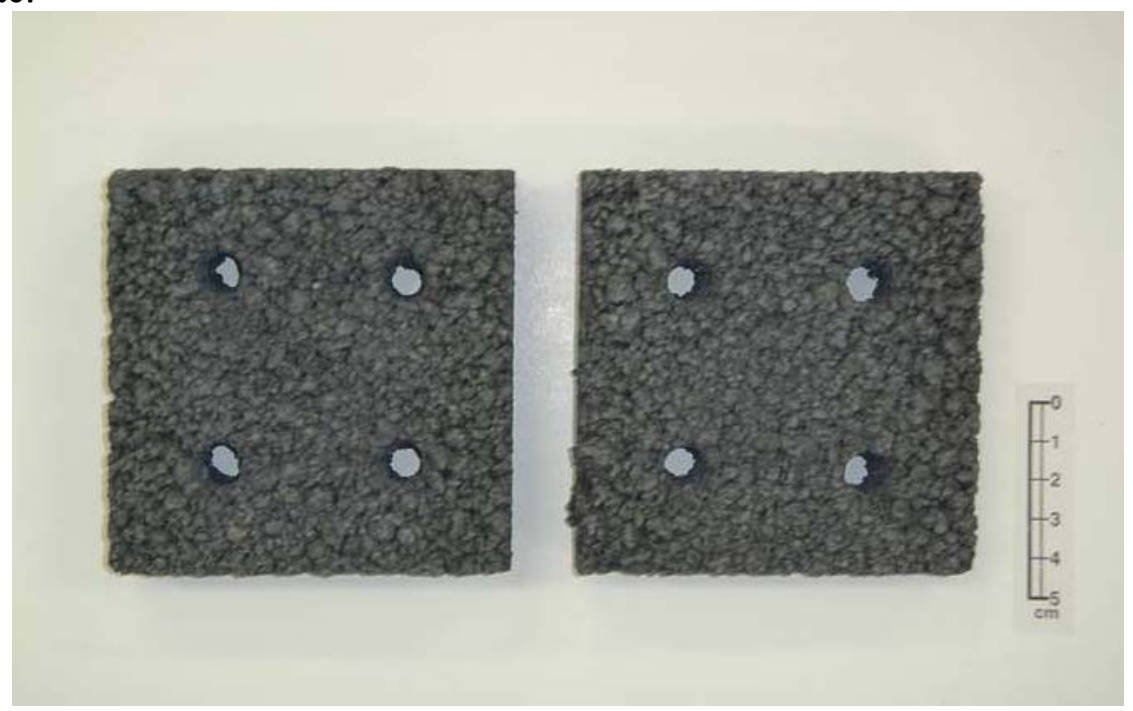

Figure 2. Plates for the field test.

\section{Results}

\section{Ultrastructure}

In a case where the proportion of CRDF was low (3\%), the surface of the sample was very smooth with few particles (Fig. 3a). As the proportion of CRDF increased (20\%), carbonaceous grains were observed on the surface of the sample (Fig. 3b). In the sample with $90 \%$ of CRDF, there were many finely uneven surface structures (Fig. 3c).

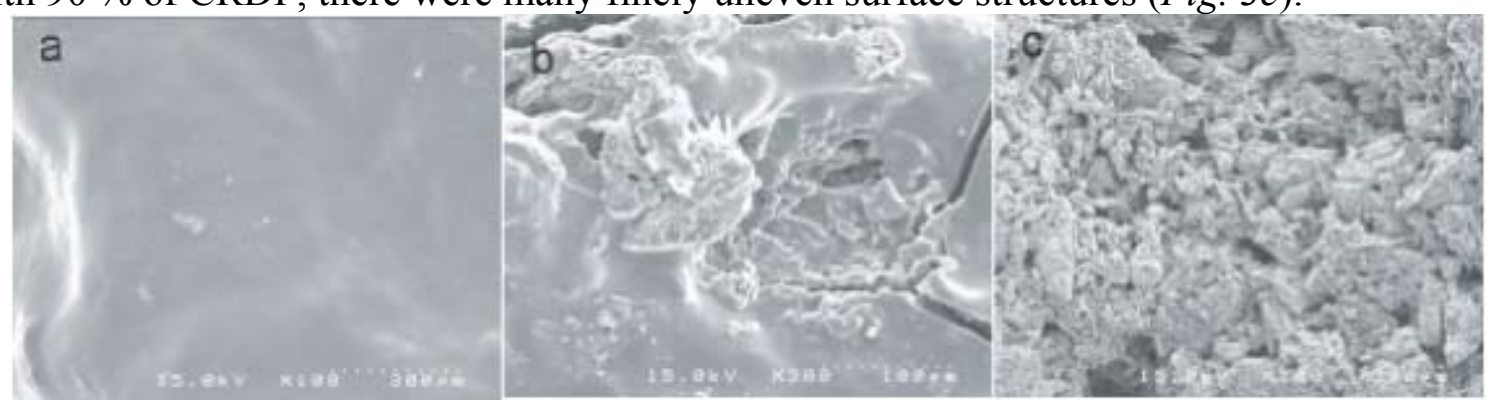

Figure 3. SEM images. a) 3\% CRDF; b) $20 \%$ CRDF; c) $90 \%$ CRDF.

\section{Water analyses}

We confirmed that none of the chemical compounds listed above were eluted out from CRDF. The $\mathrm{pH}$ and the concentrations of ionized chemical compounds in seawater after the two of the culture experiments (i.e. with and without CRDF) are shown in the Table 1. Comparing the results between these two experiments, there was no critical difference in the $\mathrm{pH}$ and the concentrations of ionized chemical compounds except for $\mathrm{NO}_{3}{ }^{-}$. In both experiments, data on $\mathrm{pH}$ indicate seawater was weakly alkaline. The concentrations of $\mathrm{NO}_{2}{ }^{-}, \mathrm{PO}_{4}{ }^{3-}$ and $\mathrm{NH}_{4}^{+}$were remarkably low. Only the concentration of 
$\mathrm{NO}_{3}{ }^{-}$was, however, notably increased in the experiment with CRDF. The ratios of TIN to RP of seawater at our field study site from July to December are shown in the Table 2. All of them were lower than the Redfield ratio.

Table 1. Water analysis in the culture experiments.

\begin{tabular}{|c|c|c|c|c|c|}
\hline & pH & $\mathrm{NO}_{3}^{-}\left(\mathrm{mg} \mathrm{L}^{-1}\right)$ & $\mathrm{NO}_{2}^{-}\left(\mathrm{mg} \mathrm{L}^{-1}\right)$ & $\mathrm{PO}_{4}{ }^{3-}\left(\mathrm{mg} \mathrm{L}^{-1}\right)$ & $\mathrm{NH}_{4}^{+}\left(\mathrm{mg} \mathrm{L}^{-1}\right)$ \\
\hline Experimental & 8.33 & 23 & $<0.1$ & $<0.1$ & $<10$ \\
\hline Control & 8.77 & $<0.1$ & $<0.1$ & $<0.1$ & $<10$ \\
\hline
\end{tabular}

Table 2. The ratios of TIN (=Ammonium + Nitrate + Nitrite) to $R P$ (=Reactive phosphorus) of seawater at our field study site from July to December.

\begin{tabular}{|lllllll|}
\hline Month & July & August & September & October & November & December \\
\hline TIN:RP & 6 & 7.3 & 9.9 & 11.2 & 8.2 & 5.2 \\
\hline
\end{tabular}

\section{Gametophyte growth rate}

The mean volumes of gametophytes of each experimental regime were plotted (Fig. 4 ). In the experiment with $5 \mathrm{~g}$ of CRDF, the growth rate was constantly low. The difference between the experiment and the control (i.e. agar only) was not clear. In contrast, in the experiment with $15 \mathrm{~g}$ of CRDF, the gametophyte growth rate was remarkably higher than the other two experiments, accelerating from the $2^{\text {nd }}$ to $3^{\text {rd }}$ week, and then decelerating and leveling-off after the $5^{\text {th }}$ week. The mean volume of gametophytes was approximately three times larger than that of the control at the beginning of $6^{\text {th }}$ week.

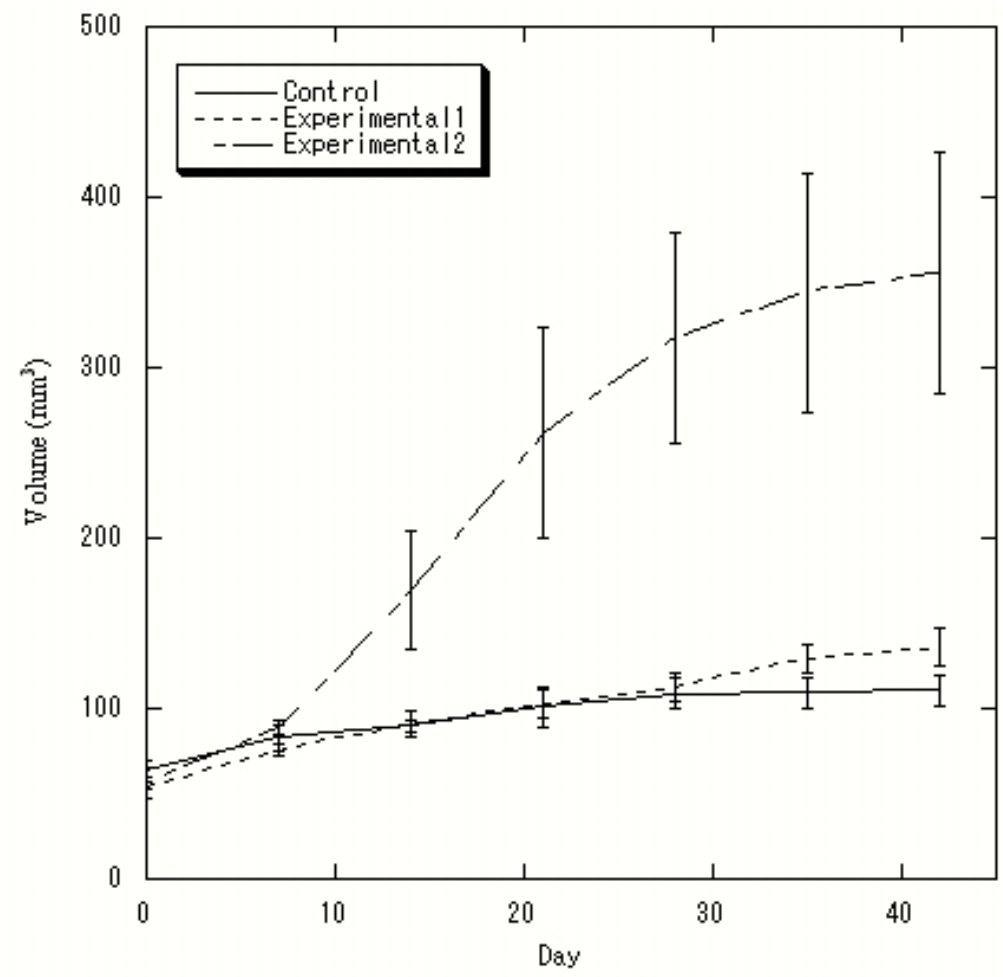

Figure 4. The growth rates of male gametophytes of D. tenuissima with and without CRDF. Experimental 1: with $5 \mathrm{~g}$ of CRDF; Experimental 2: with $15 \mathrm{~g}$ of CRDF; Control: 1\% agar only. Mean $\pm S D(n=5)$. 


\section{Field tests}

The numbers of macroalgae that were growing on the surface of the test plates after two months are shown in the Fig. 5. The results of the field tests might be appropriately shown by these numbers as a whole because only one species of a green alga, Ulva conglobata Kjellman, migrated on the plates by the end of this study and their size was still too small to compare their size. Ulva is an isomorphic alga. So we identified individuals, but, did not distinguish gametophytes and sporophytes. A large number of U. conglobata plants ( 85 individuals) were observed on the plate with $8.20 \%$ of CRDF. Their numbers decreased as the percentage of CRDF. We found no $U$. conglobata plant on the plate that did not include CRDF at the end of this study. We tested another series of plates which were different in shape and located in a different place within the same study site. The results were similar to those here (data not shown).

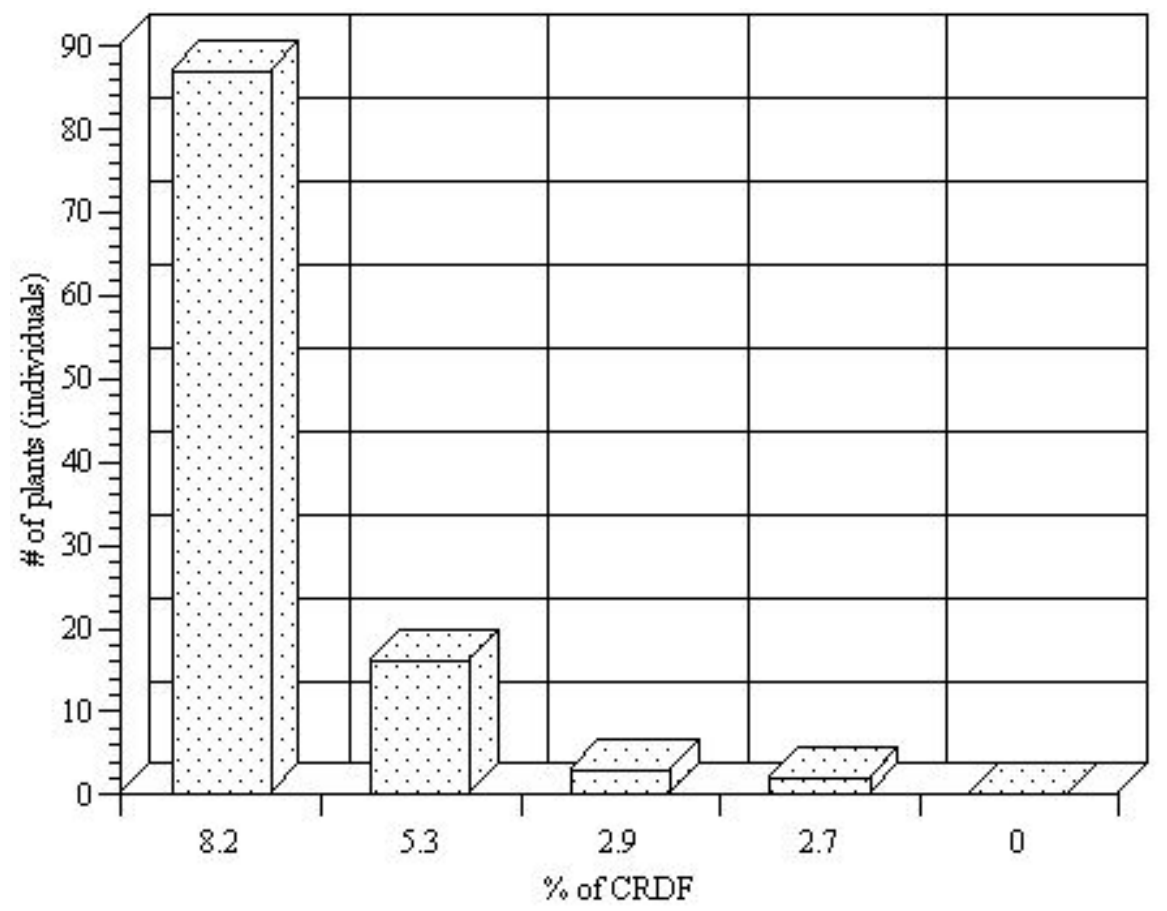

Figure 5. The numbers of Ulva conglobata plants migrated on the test plates (Fig. 2) after 2 months.

\section{Discussion}

Our culture experiments suggest that some substances eluted from CRDF are effective to accelerate the growth rate of algae (Fig. 4). The effects of dissolving substances seem to continue at least for several weeks. During the culture experiments, we have scarcely observed sexual reproduction. Therefore, most of the energy that Derbesia plants have might be spent for the growth. The growth was, however, inhibited by excess amounts of CRDF (e.g. $100 \mathrm{~g}$ per vessel in our experimental method) (data not shown). Thus, there might be the most suitable condition for growth of algae with this material.

In general, shallow-seawater habitats have relatively low N:P ratios [1]. Therefore, nitrogen is the element that most frequently limits algal growth in the sea [8]. Our 
analyses of seawater at our field study site confirm nitrogen is limited (Table 2). Meanwhile, our analyses of seawater after the culture experiments suggest that CRDF might supply nitrogen short as the form of nitrate (Table 1). Thus, in our culture experiments, the growth of Derbesia plants might be accelerated by such nitrogen. It has been suggested that nitrogen supply will be also an important constraint on global responses of terrestrial plants to elevated $\mathrm{CO}_{2}[9,14]$. Another possible reason is that the quality of seawater is improved by the carbonaceous material that works as an absorbent. However, it might be less likely because there are few factors that cause serious water pollution near our field site (seawater is usually very clear). The surface structures of CRDF can not be considered here because the material was completely covered with agar. Additionally, we should note that the $\mathrm{pH}$ of seawater is not dramatically changed by CRDF (Table 1). It would be important for many aquatic organisms including algae (see [18]). The $\mathrm{pH}$ of seawater after the culture experiments appear to be slightly higher than the average $\mathrm{pH}$ of seawater (i.e. 7.7 ranging from 7.2 to 8.2). This might be caused through the rapid abstraction of $\mathrm{CO}_{2}$ from seawater during photosynthesis of algae (see [1]).

Also, our field tests suggest that CRDF is useful to introduce seaweeds in the field, and that there may be the most suitable combination of CRDF and other materials for seaweeds to migrate on the plates, because, as the percentage of CRDF was increased, the number of migrated plants was increased (Fig. 5). In this study, we adduce the following three major reasons for these results. 1) Some of chemical compounds eluted from CRDF may be effective for seaweeds to grow on the plates as shown in the culture experiments. 2) CRDF may improve the quality of seawater as good adsorbent. 3) Because the surface of CRDF is rich in ultrastructural pores (Fig. 3) it may have a good affinity for zoospores of seaweeds as shown in activated carbon for marine microorganisms [2].

We have observed only Ulva conglobata plants on the test plates during our field experiment. It may be because they can flourish at the early stage of the secondary succession as a pioneer species. Actually, some other species were found on the plates after this study (e.g. Colpomenia bullosa (Saunders) Yamada). At our field study site, Sargassum fusiformis (Harvey) Sethchell, which is an economically important perennial brown alga as a good food material in eastern Asia (e.g. Japan and Korea), is one of the major dominant species. We try to introduce such species with future long-term endurance tests. There are many other reports on methods to restore seaweed forests so far (e.g. [11]). The most important merit of our study is that we use municipal solid waste (MSW) as the main ingradient. This is useful not only to reduce the costs, but also to solve two important environmental problems: atmospheric $\mathrm{CO}_{2}$ and biodiversity. In this sense, our approach is a new type of win-win (reconciliation) ecology in marine ecosystems [15].

Acknowledgements. This work is funded by a grant-in-aid from the Ministry of Education, Culture and Science of Japan. 


\section{REFERENCES}

[1] Brown E., Colling A., Park D., Phillips J., Rothery D., Wright J. (1995): Seawater: Its composition, properties and behaviour. - Butterworth-Heinemann, Oxford.

[2] Fukuhara T., Abe I., Somiya I. (2001): Effect of pore structure of activated carbon on attached biomass. - Tanso 199: 155-160 [in Japanese].

[3] Gendebien A., Leavens A., Blackmore K., Godley A., Lewin K., Whiting K.J., Davis R., Giegrich J., Fehrenbach H., Gromke U., del Bufalo N., Hogg D. (2003): Refuse derived fuel: Current practice and perspectives. - WRc plc, Swindon.

[4] Hillebrand H., Dürselen C.D., Kirschtel D., Pollingher U., Zohary T. (1999): Biovolume calculation for pelagic and benthic microalgae. - Journal of Phycology 35: 403-424.

[5] Hutchings J.A., Reynolds J.D. (2004): Marine fish population collapses: consequences for recovery and extinction risk. - BioScience 13: 297-309.

[6] Kim M., Choi J., Kang S., Cho J., Jin H., Chun B., Hong Y. (2004): Multiple allelopathic activity of the crustose coralline alga Lithophyllum yessoense against settlement and germination of seaweed spores. - Journal of Applied Phycology 16: 175-179.

[7] Levinton J.S. (2001): Marine biology: Function, biodiversity, ecology. - Oxford University Press, Oxford.

[8] Lobban C.S., Harrison P.J. (1994): Seaweed ecology and physiology. - Cambridge University Press, Cambridge.

[9] Luo Y., Su B., Currie W.S., Dukes J.S., Finzi A., Hartwig U., Hungate B., McMurtrie R.E., Oren R., Parton W.J., Pataki D.E., Shaw R., Zak D.R., Field C.B. (2004): Progressive nitrogen limitation of ecosystem responses to rising atmospheric carbon dioxide. - BioScience 54: 731-739.

[10] Myers R.A., Worm B. (2003): Rapid worldwide depletion of predatory fish communities. - Nature 423: 280-283.

[11] Ooishi M., Shiraishi M., Otani S. (1998): Fixation of marine microorganisms on carbon fiber. The Bulletin of School of High-Technology for Human Welfare Tokai University 8: 79-88 [in Japanese].

[12] Pandit V. (1994): Coastal fishery projects. - A. A. Balkman, Rotterdam.

[13] Redfield A.C. (1958): The biological control of chemical factors in the environment. American Scientist 46:205-221.

[14] Reich P.B., Hobbie S.E., Lee T., Ellsworth D.S., West J.B., Tilman D., Knops J.M.H., Naeem S., Trost J. (2006): Nitrogen limitation constrains sustainability of ecosystem response to $\mathrm{CO}_{2}$. - Nature 440: 922-925.

[15] Rosenzweig, M.L. (2003): Win-Win Ecology: How the earth's species can survive in the midst of human enterprise. - Oxford University Press, Oxford.

[16] Sears J.R., Wilce R.T. (1970): Reproduction and systematics of the marine alga Derbesia (Chlorophyceae) in New England. - Journal of Phycology 6: 381-392.

[17] Tatewaki M., Nagata K. (1970): Surviving protoplasts in vitro and their development in Bryopsis. - Journal of Phycology 6: 401-403.

[18] van den Hoek C., Mann D.G., Jahns, H.M. (1995): Algae: an introduction to phycology. Cambridge University Press, Cambridge. 